\title{
Whatever happened to repeat victimisation?
}

Ken Pease ${ }^{1}$ University of Derby

Dainis Ignatans University of Huddersfield

Lauren Batty

\section{Abstract}

Crime is concentrated at the individual level (hot dots) as well as at area level (hot spots). Research on repeat victimisation affords rich prevention opportunities but has been increasingly marginalised by UK policy makers and implementers despite repeat victims accounting for increasing proportions of total crime. The present paper advocates a resurgence of interest in research and initiatives based on the prevention of repeat victimisation.

Keywords: repeat victimisation, crime concentration, victimisation inequality, evidencebased criminology.

\section{A Brief History of Repeat Victimisation Research and Practice}

The last decade of the twentieth century witnessed a vogue for applicable research and action against repeat victimisation by crime, documenting its extent, distribution across time, and the opportunity for focused crime prevention which action against repeat victimisation represented. With hindsight, two studies piqued interest in the approach. First, a residential burglary prevention project on the Kirkholt estate in Rochdale UK brought about dramatic reductions in that crime. While the project was contentious at the time, the premise on which it was based, namely that for many homes victimisation presages further victimisation, was well evidenced. On the Kirkholt estate, long identified as a high crime area, prior burglary was found to be the best single predictor of burglary. The scale of repeat victimisation was found to be immense. It can be illustrated as follows. If one started counting burglaries in January, by December of the same year the majority of all burglaries would be of homes that had been burgled at least once before during that year. In other words, preventing only repeats would, within twelve months, come to prevent the majority of all burglaries. Given scepticism that the dramatic reductions achieved were the result of the strategy of protecting homes against repeat offences, the Home Office commissioned a review of the data. This confirmed that the reduction was indeed driven by a decline in repeats. Despite its inevitable imperfections as the first project of its kind, Kirkholt can safely be taken as proof of concept, that prompt action to prevent repeat crime was a promising crime prevention tactic.

\footnotetext{
${ }^{1}$ k.pease@derby.ac.uk
} 
The Kirkholt estate forms one small part of one town in the north of England. Attempts at replication enjoyed mixed success. The more disappointing results were often attributable to implementation failure (see Tilley 1999 for a discussion). The key question immediately post-Kirkholt concerned the general relationship between repeats and an area's total crime rate. If it turned out that high crime areas were those hosting most repeats, the prevention of repeats could do service generally as a crime reduction policy, with the crucial advantage of automatically directing effort to the most crime challenged areas, without stigmatising them, the focus being on the victim not the area. At Kirkholt, the risk of a repeat was found to diminish with time elapsed since the previous crime. If this were the case elsewhere, it would mean that attention to victimised homes need only be temporary. This has obvious importance for optimising the deployment of scarce policing and other resources. The approach was characterised as drip feeding crime prevention effort because it simply set up a process whereby effort was focused upon recent victims and their immediate neighbours. The effort thereby tracks the changing scale and location of the problem. By identifying recent victims as those at greater risk, victim support and crime prevention functions are brought together (Farrell and Pease 1997) But here we get ahead of ourselves in stressing the advantages of an approach yet (in 1990) to be found relevant across the board.

The speculation that had to be tested was that high crime areas were characterised by a high proportion of repeats. If that were the case, then prevention of repeats as a strategy was up and running. Trickett et al. (1992) sought to test the idea. They analysed the national victimisation survey (then called the British Crime Survey, latterly the Crime Survey for England and Wales). They looked at the extent to which two variables contributed to any small area's crime rate. The first variable was the proportion of people or households victimised (prevalence). The second was the number of victimisations per victimised person or household (concentration). Either or both could in principle yield the observed inter-area variation in crime rates. Their conclusion they reached was that an area's rate of crime was determined substantially, arguably primarily, by its rate of repeats (concentration at the individual level). It should be stressed here that the Trickett results suggested that repeats were the primary determinant of crime rate. The conclusion is here stated over-cautiously, to preclude descent into diversionary methodological niceties about the counting of repeats. The work was described by the distinguished criminologist Wesley Skogan in the following terms

"Probably the most important criminological insight of the decade has been the discovery in a very systematic fashion of repeat multiple victimization. This has tremendous implications both for criminological theory and...practice in the field" (Skogan, cited in Brady 1996 p3).

By the turn of the millennium one might reasonably have foreseen the emergence of a crime reduction policy with the prevention of repeats at its core. Extensive attempts were made to bring the findings of research and initiatives on the ground to a wider audience (Bridgeman and Sampson 1994; Pease and Laycock 1996; Bridgeman and Hobbs 1997; Pease 
1997; Laycock 2001). Yet the first two decades of the new millennium have seen a progressive decline in attention to repeat victimisation in policy formulation, although not in research.

Later in this paper we will bemoan the decline of interest in repeat victimisation and argue for its resurrection. At this point we present a brief outline of some post 2000 advances in understanding repeat victimisation. The purpose in mentioning them here is to assert that if the strategy were fit for purpose in 2000 , it is far more so now. Some of the more important advances are as follows.

1. Wherever crime data permits its identification, repeat victimisation accounts for a non-trivial proportion of total crime (Farrell and Bouloukos 2001; Kleemans 2001; Mawby 2001; Tseloni et al. 2004; Farrell et al. 2005; Sidebottom 2011). Further work reporting similar results in Nigeria is in preparation.

2. Two ways of thinking about repeats have been distinguished. The first, the 'flag' account, contends that repeats simply flag people or places that were always vulnerable to crime. The alternative (the boost account) proposes that victimisation increases the risk of further victimisation (Tseloni and Pease 2003; Johnson 2008). There are plausible reasons for the boost account to contribute to patterns of repeat victimisation For example an offender's increased knowledge of the target and of goods worth stealing which remain in the home invites repetition by the offender. As one Glasgow burglar tersely put the reason for returning, 'big house, small van'. Returning may also target replaced goods (Clarke et al. 2007). In short, the evidence is unsurprisingly that both flag and boost factors contribute to repeat victimisation patterns. Those who commit repeats are overwhelmingly the same people as those who committed the first (Bernasco 2008). This is further suggestive evidence of boost factors being at work. If the flag account were the whole story, one would expect more cases in which different offenders committed initial and repeat offences (under any tenable assumption about the population of active burglars). For offences like domestic violence, the boost account is self-evidently important.

3. Extensive repeat victimisation has been demonstrated for offences other than burglary, for example robbery (Matthews et al 1999), criminal damage to schools (Burquest et al 1992) and personal violence (Tseloni and Pease 2003, 2004). Clearly domestic violence represents the most obvious example of chronic victimisation (Walby and Myhill 2001; Walby and Allen 2004; Walby et al. 2016). Intensive study of hate crime and cybercrime through a repeat victimisation lens is overdue.

4. Decay curves found in burglary events, wherein repeats are shown to occur swiftly, have also been identified for other offences; robbery (Matthews et al 2001), networks attacks on computer systems (Moitra and Konda 2004) and domestic violence (Pease, in preparation). Johnson and Bowers (2014) provide additional evidence of the decay curve for domestic burglary. 
5. A systematic review of initiatives attempting crime reduction by the prevention of repeats confirms the viability of well-implemented enterprises of this type (Grove et al. 2014).

The above outlines only some of the progress in understanding repeat victimisation realised over the last twenty years. More recent and comprehensive treatment of applicable research is to be found in Farrell and Pease (2017) and Pease and Farrell (2017). To reiterate, the reason for including the above list is that however attractive repeat victimisation prevention was as a strategy when it was in vogue, its attraction should be greater now.

Let us now return to the topic promised by the title. Figure 1 shows trends in published research on repeat victimisation, in relation to attention to near repeats. The numerical resurgence of repeat victimisation publications shown surprised the writers but afford them hope that the time is ripe for an attempt to revive policy interest in the approach. One may speculate that the rise in the study of near repeats has evoked renewed interest in direct repeats.

A search of the Google Scholar database using an advanced search tool identified the number of articles published each year as work on repeat victimisation really took off in the 1980s. Whilst it is clear that these works exclude those which have not been made accessible online, it gives a good indication of the trends in interest about this topic. The advanced search tool was used to identify the papers with the following phrases in their titles; 'Repeat Victimisation', 'Repeat Victimization' and 'Near Repeat'. It became clear that the difference in spelling of victimisation was important to consider if all results were to be found. The importance of this will later be discussed.

In figure 1 is displayed the number of papers meeting the criteria found via Google Scholar, by year. It is clear from Figure 1 that research on repeat victimisation rapidly increased until the millennium and then saw a fall in the early 2000's; around the time when research on near repeats began to emerge. This could suggest that research on near repeats could have been viewed as an extension of that on direct repeats although the two phenomena differ in their operational implications. The first entry for research on near repeats on Google Scholar was in 2003 since when their numbers have consistently increased. The trends suggest that published research on near repeats will come to exceed that on direct repeats within a few years. Interestingly there is a minimal overlap between the two research agendas. Only $8 \%$ of Google Scholar entries captured in this exercise addressed both repeat and near repeat victimisation in the title. Research appears to be addressed to one or other of the phenomena, few to both.

The alternative spellings of victimisation/victimization offers a little insight as to where the interest in the topic lies. Victimization is an American variant so we would assume that $74 \%$ of the entries for direct repeats would be of US or Canadian origin in authorship or place of 
publication. The US variant has dominated in recent years. So, does this mean that direct repeat research from the UK is decreasing? Well, no. Further investigation of the 'Victimization' entries reveals that some of the them were cited as being published in the UK. So, we cannot gauge a true perception of continental trends because this could mean that the affiliations of the authors of the articles remain substantially in UK institutions.

Figure 1. Trends in Repeat and Near Repeat Publications on Google Scholar 1988-2017

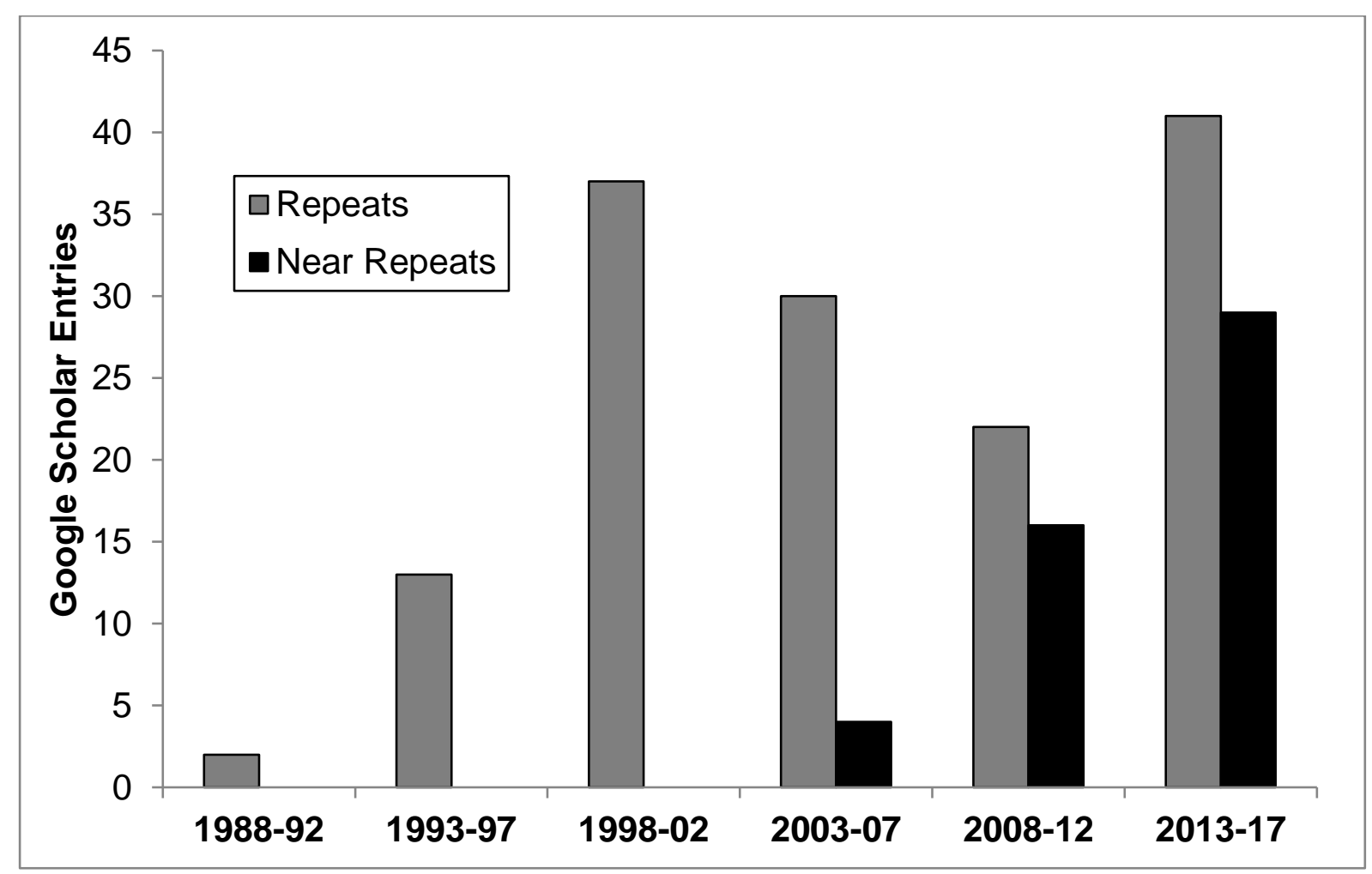

Whilst Google Scholar is useful for indicating trends of research it has its limitations. It is not clear what the absolute figure of articles is year by year based on not all of them being available online. This can specifically be an issue in the case of earlier years. There have also been issues regarding accuracy of citations reported by users in the past. Many users contend that entries are not reflective of the true number of publications per country and citations can be missed due to the insertion of punctuation (not applicable in this case due to absence of punctuation in search) (Konkiel, 2014: Martín-Martín, Ayllón, Orduña-Malea, Delgado López-Cózar, 2014)

Paradoxically, as noted earlier, the reduction in attention to direct repeats in policy pronouncements might be a function of an increase in attention to near repeats, the phenomenon that risk leaks from one victimised location to those nearby. The near repeat phenomenon is one of the pillars on which predictive police patrolling rests. The immensely 
useful near repeats calculator ${ }^{2}$ devised by Jerry Ratcliffe of Temple University operates purely on distance between events. It does not distinguish between same and different victimised people or homes. Looking at direct repeats as the extreme case of near repeats loses a great deal, as will be argued later.

\section{Disappearance of Repeat Victimisation from Official Discourse}

We turn now to document our claimed neglect by government of repeat victimisation. In annual published crime statistics we have moved from an explicit consideration of the topic to its total disappearance from recent volumes. What remains are tables allowing a reader with the necessary skills to make calculations which yield a a partial representation of the extent of repeat victimisation. Even when repeat victimisation featured in official statistics, it did so in a form some way distanced from a depiction commensurate with its scale. The crucial figure in Crime Statistics documented the proportion of households which suffered more than one victimisation of the same type, irrespective of how many times it had been victimised, so a home burgled ten times was counted the same as a household burgled twice, an assault victim attacked ten times as one attacked twice. Let us not neglect the first problem noted in that sentence. Only repeats within a crime category were counted as such. A household suffering one car theft, one criminal damage and a burglary was not repeatedly victimised when counted in this way. So even in the heady days when repeat victimisation was getting some attention in crime statistics and policy, the statistics misrepresented the reality on the ground.

The most dramatic illustration of how marginalised the topic of repeat victimisation has become in official thinking may be found in the Home Office's Modern Crime Prevention Strategy of 2016 (Home Office 2016). In a document of fifty pages we find a single mention of repeat victimisation which reads as follows. We seek "more efficient identification of victims and potential victims, and reducing repeat victimisation" (p28). Disappointing as this meagre mention is in itself, the whole point of repeat victimisation is that it provides operationally useful identification of potential victimisation. Such identification occurs by dint of a call for police service. It is thus simple, usually prompt and does not entail any disclosure of personal information beyond report to the police. The promptness is especially important given the time decay curve of victimisation described earlier.

Returning to the scanty treatment of repeat victimisation in the Home Office's Modern Crime Prevention Strategy, the section in which repeat victimisation is (briefly) mentioned is truly bizarre. It strongly suggests that its writer has no appreciation of the extent and implications of the body of research and practice available. The section in which repeat victimisation is to be found is about "Profit as a Driver of Crime". The section focuses on "preventing crime by targeting criminal profits" (p27). This makes sense as a context for discussion of repeat victimisation only insofar as any successful crime reduction tactic denies criminals the profits of crime. In brief, while its disappearance from Crime Statistics marks the demise of repeat victimisation from official thinking, the Modern Crime

\footnotetext{
${ }^{2}$ http://www.cla.temple.edu/ci/resources/near-repeat-calculator/accessed Jan 22, 2018.
} 
Prevention Strategy marks the burial of the prevention approach that was so lauded two decades earlier.

\section{Is there less of it about?}

The reader familiar with the cross-national crime drop of the last thirty years will at this point be wondering whether the drop makes advocacy of a neglected crime reduction strategy unnecessary or unimportant. In fact what has happened (in England and Wales at least) is that while repeat victimisations have fallen in absolute terms, they have fallen proportionately less than one-off victimisations, with the consequence that the prevention of repeats is now even more important as a crime control tool than it was when the crime drop began. We rehearse relevant evidence below.

Analyses of the Crime Survey and Wales (CSEW) have shown that the chance of being victimised has fallen. Alongside this, repeat victims are victimised less frequently now. The average number of victimisations of the ten per cent most victimised households in England and Wales has dropped from 7.7 in 1994 during the 'crime peak' to just 3.2 in 2012. Over the same period, the proportion of total victimisation experienced by the same people has increased from 57\% in 1994 to 72\% in 2012 (Ignatans \& Pease, 2015) indicating that inequality in victimisation has increased.

A closer look into the distribution of victimisation amongst those most victimised reveals that just one per cent of the population is now accounting for over a half of all personal victimisation (52\% in 2012 up from 42\% in 1994), and over a quarter of property crime (33\% up from $22 \%$ ) and vehicle related victimisation (27\% up from $16 \%$ in 1994) (Ignatans \& Pease, 2016a). The total burden of crime has declined but the most victimised are accounting for an increasing proportion of that burden. Those repeatedly victimised differ in their socio-demographic in respect to age, marital status, employment characteristics, occupancy numbers within a residence and property composure (Ignatans \& Pease, 2015, 2016a). So what? How can we think of repeat victimisation in terms of distributive justice?

In general, repeat victims have the same characteristics that distinguish victims from nonvictims. They just have more of those attributes. Differentially providing subsidised crime prevention goods and services on the basis of demography is divisive and probably impractical. Distributing on the basis of prior victimisation is not because it is done on the basis of their misfortune not their personal attributes. A parallel may be made with the provision of medical help.

Some have criticised the repeat prevention strategy as allowing an offender 'one free go' because it does not deploy prevention until after an offence. However, just as in public health, the provision of crime prevention goods and services to everyone in advance of a victimisation where economically practicable is not excluded by the strategy outline here, 
though it is easier to envisage for property than personal crime. The balance between universal provision of help and the prevention of repeats becomes increasingly tilted in favour of the latter, the lower the prevalence of victimisation. If one household in two is victimised, the anticipatory provision of help is irrelevant in $50 \%$ of cases. If only one household in ten is victimised, the anticipatory provision of help is irrelevant in $90 \%$ of cases.

To return to the CSEW data, the increase in the proportion of victimisation experienced by the most victimised top one per cent of the population after the crime peak is graphically represented in Figure 2 below.

Figure 2. Proportion of personal, property and vehicle victimisation as experienced by the top percentile of victimised households, CSEW Sweeps 1994-2017.

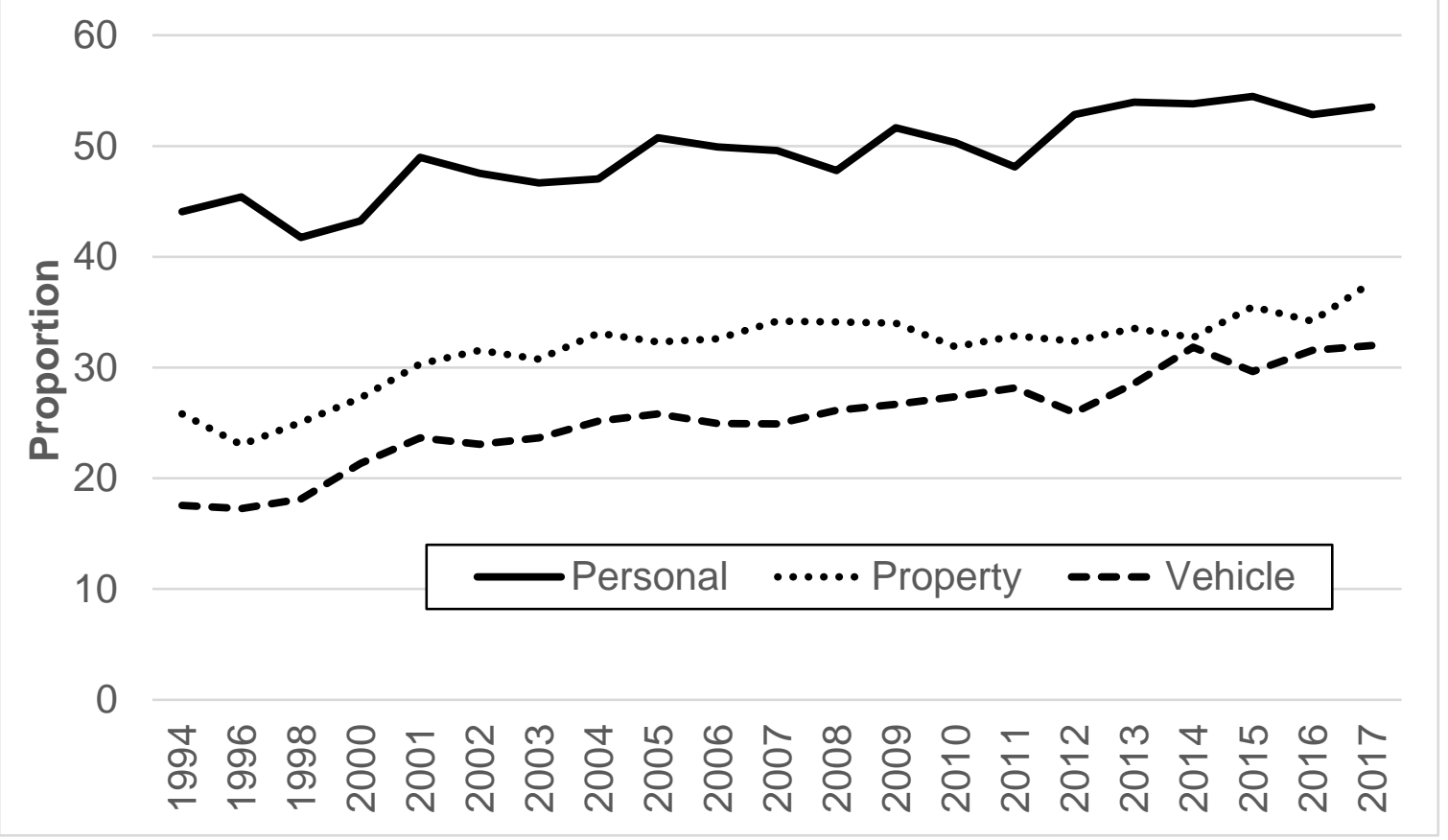

The seriousness of crime suffered by repeat victims, as per their own judgements, is also found to be disproportionately high. Utilizing an underused measure of CSEW, victim judgements of offences they experienced, the most 'harmed' $10 \%$ of the population suffered $45 \%$ of total harm (Ignatans and Pease, 2016b) further expanding the research evidence base for the proposal to focus crime prevention effort on those previously victimised.

Utilizing the International Crime Victims Survey (ICVS) where data from fifteen countries were comparable across sweeps encompassing the crime peak and drop period, it was found that the proportion of total personal victimisations experienced by the most victimised $1 \%$ increased from 32 per cent in 1992 to 36 per cent in 2000 . The proportion of property related victimisation experienced by the one per cent of most victimised increased from 33 to 48 per cent with vehicle related victimisation also increasing from 18 to 22 per cent in the same time period. Similar personal and socio-demographic characteristics were 
found to differ between the 'super-target' victims and the general population (Pease and Ignatans, 2016).

There surely could not be a more obviously relevant enterprise than reducing the concentration of crime on 'super-repeats'. With repeat victims being easily identifiable 'vital few' without whom most crime would not be taking place, it is inevitably to be expected of the criminal justice system that it focuses on these people in order to reduce crime in a cost efficient manner while utilising the vast body of evidence available and to distribute risks and harms more equitably (Ignatans and Pease, 2018).

\section{Why Resurrect Repeat Victimisation as a Crime Prevention Approach?}

While the concentration of crime across the population has become more unequal than ever, and despite a systematic review showing that the prevention of repeats is a viable approach to crime reduction (Grove et al. 2014), it is demonstrated above that policy attention to repeat crime has diminished to the point of almost total disappearance. In the case of government attention, it has sunk with little trace, only a few bubbles on the surface indicating where it foundered. It is asserted here that a renewed emphasis on the reduction of direct repeats as an essential part of any crime reduction strategy is overdue. Arguments for this are as follows.

1. For much emerging crime, spatial proximity is irrelevant. This means that, while the notion of near repeats in spatial terms becomes less applicable, the notion of direct repeats does not. It may be that near repeats can be reconceptualised in other terms (for instance in terms of IP addresses) but the processes of target selection in cybercrime and cyber-enabled crime are distinctive in ways which make direct repeats more important. For example, one to many communications are easy in cyberspace and difficult in physical space. This means that while in physical space, offenders select targets, in cyberspace targets select themselves. Send emails to a thousand people offering untold wealth in exchange for a smaller sum necessary to release that wealth (the advance-fee scam). The ten people who are gulled have selected themselves. Insofar as they are gullible generally, they will become repeat victims. There is no reason to suppose there is a strong spatial correlate of gullibility (Titus and Gover 2001).

2. In violent or sexual crime in physical space, people carry their vulnerability around with them. While some crimes have spatial referents (attacks on mosques or synagogues or convenience stores run by people of Asian origin), others do not. Women carry their risk of sexual assault around with them. The current interest in identifying vulnerable people often involves their personal characteristics or behaviour, which they possess wherever they are (Keay and Kirby 2017). . The more precise the location, the clearer are the action possibilities. Maps without recent 
crimes depicted on them provide no obvious starting points for investigation. The less focused the attention (on places or people), the greater the scope for stigmatising an area. Predictive patrolling algorithms may be criticised for stigmatising areas. In contrast, attention to recent victims is justifiable in terms of the risk at which they stand. The first writer when faced with a police audience often asks 'Mapping has just identified a crime hot spot. Go and stand in the middle. What do you do next?' David Weisburd, properly regarded as doyen of criminologists of place, proposed (Weisburd 2015) that "for a defined measure of crime at a specific micro geographic unit, the concentration of crime will fall within a narrow range of bandwidths of percentages for a defined cumulative proportion of crime" (p138). The Weisburd law of crime concentration thus reflects the issues of clustering. Cory Haberman and colleagues (Haberman et al. 2016) tested Weisburd's Law for street robberies across different 'temporal scales', i.e. clock time, date and season. Their data supported the Law. However although the same small proportion of street segments hosted a large proportion of street robberies, they were not necessarily the same street segments. The hot spots were slippery. Crime comes in spates. The parallel with animal foraging, where an animal stays in an area until circumstances change (habitat becomes less nourishing, the risk of predation increases) demands movement within and across areas, generating the observed slipperiness (Johnson 2014).

There seems no reason to reprise the argument of this paper. It is to recognise the prevention of repeat victimisation as an important, neglected enterprise. A suggested first step would be an audit across police forces revealing the extent of repeat victimisation, within and across crime type. This would incidentally reveal any obstacles to identifying repeats which remain in police data systems. It would reveal anew the fact long hidden in plain sight, that victimisation begets victimisation.

\section{References}

Bernasco W. Them Again? (2008) Offender Involvement in Repeat and Near Repeat Burglaries European Journal of Criminology 5, 411-431.

Brady T.V. (1996) Measuring What Matters. Washington DC. National Institute of Justice. Bridgeman, C. and Sampson, A. (1994) Wise After the Event: Tackling Repeat Victimisation.London: Home Office.

Bridgeman, C. and Hobbs, L. (1997) Preventing Repeat Victimisation: the police officer's guide. London: Home Office. 
Burquest R., Farrell G. and Pease K. (1992) 'Lessons from schools: some schools are repeatedly vandalised, and burgled. Is there a pattern which police could interrupt?' Policing, 8, 148-155.

Chatterton M., Forrester D. and Pease K. (1988) The Kirkholt Burglary Prevention Demonstration Project, Rochdale. Crime Prevention Unit Paper 13. London: Home Office

Clarke R.V., Perkins E. and Smith D.J. jr. (2007) 'Explaining Repeat Residential Burglaries: An Analysis of Property Stolen'. Crime Prevention Studies 12, 11132.

Farrell, G. and Bouloukos, A.C. (2001). 'A cross-national comparative analysis of rates of repeat victimization'. In. G. Farrell and K. Pease (eds) Repeat Victimization : Crime Prevention Studies, Vol. 12 , 5-25. Monsey, NY: Criminal Justice Press.

Farrell G. and Pease K. (1997) 'Repeat Victim Support'. British Journal of Social Work, 27, 101-113.

Farrell G. and Pease K. (2017) ‘Preventing Repeat and Near Repeat Crime Victimisation'. In N.Tilley and A. Sidebottom (eds) Handbook of Crime Prevention and Community Safety. London: Routledge.

Farrell G., Tseloni A. and Pease K. (2005) 'Repeat Victimization in the ICVS and the NCVS'. Crime Prevention and Community Safety. 3, 7-18.

Grove L., G.Farrell, D.Farrington and S.D. Johnson (2014) Preventing Repeat Victimisation: A Systematic Review. Stockholm:Swedish National Council for Crime Prevention.

Haberman C.P., Song E.T. and Ratcliffe J.H. (2016) 'Assessing the Validity of the Law of Crime Concentration across Different Temporal Scales'. Journal of Quantitative Criminology, DOI 10.1007/s10940-016-9327-4

Konkiel, S. (2014, July 23). 4 reasons why Google Scholar isn't as great as you think it is [Web log post]. Retrieved from http://blog.impactstory.org/googe-scholar-profiles-fail/

Ignatans, D. and Pease, K. (2018) 'Crime Concentrations: Hot Dots, Hot Spots and Hot Flushes'. In: The Oxford Handbook of Environmental Criminology. Oxford, UK: Oxford University Press.

Ignatans, D. and Pease, K. (2016a) 'Taking Crime Seriously: Playing the Weighting Game.' Policing: a Journal of Policy and Practice, 10 (3), pp. 184-193.

Ignatans, D. and Pease, K. (2016b) 'On whom does the burden of crime fall now? Changes over time in counts and concentration.' International Review of Victimology, 22 (1), pp. 5563. 
Ignatans, D. and Pease, K. (2015) 'Distributive Justice and the Crime Drop'. In: The Criminal Act: The Role and Influence of Routine Activity Theory. London, UK: Palgrave Macmillan. pp. 77-87.

Johnson S.D. (2008) 'Repeat burglary victimisation: a tale of two theories'. Journal of Experimental Criminology, 4, 215-240.

Johnson, S.D., and Bowers, K.J. (2014). ear Repeats and Crime Forecasting'. In G. Bruinsma, D. Weisburd (Eds.), Encyclopedia of Criminology and Criminal Justice. New York: Springer.

Johnson S.D. (2014) 'How do offenders choose where to offend?

Perspectives from animal foraging'. Legal and Criminological Psychology, 19, 193-210

Keay S. and Kirby S. (2017) 'Defining Vulnerability: From the Conceptual to the Operational.' Policing, 28, 1-11.

Kleemans E.R. (2001) 'Repeat Burglary Victimisation: Results of Empirical Research in the Netherlands'. In G.Farrell and K.Pease (eds) Repeat Victimisation: An Overview. Guilderland NY: Harrow and Heston.

Laycock G.K. (2001) 'Hypothesis Based Research: The Repeat Victimisation Story'. Criminal Justice 1, 59-82.

Martín-Martín, A.; Ayllón, J.M.; Orduña-Malea, E.; Delgado López-Cózar, E. (2014). Google Scholar Metrics 2014: a low cost bibliometric tool. EC3 Working Papers, 17: 8 July 2014.

Matthews R., Pease C. and Pease K. (1999) 'Repeat Victimisation of Banks, Building Societies, Betting Shops and Jewellers: Theme and Variations'. In G.Farrell and K.Pease (eds) Repeat Victimisation: An Overview. Guilderland NY: Harrow and Heston.

Mawby R.I. (2001) 'The Impact of Repeat Victimisation on Burglary Victims in East and West Europe'. In G.Farrell and K.Pease (eds) Repeat Victimisation: An Overview. Guilderland NY: Harrow and Heston.

Moitra S.D. and Konda S.L. (2004). 'An empirical investigation of network attacks on computer systems'. Computers and Security, 23, 43-51.

Pease K. (1997) Repeat Victimisation: Taking Stock. Crime Detection and Prevention Paper 90. London: Home Office.

Pease K. and Laycock G. (1996) Reducing the Heat on Hot Victims.Canberra, Australian Institute of Justice. 
Pease, K. and Ignatans, D. (2016) 'The global crime drop and changes in the distribution of victimisation.' Crime Science. ISSN 2193-7680

Pease K. and Farrell G. (2017) 'Repeat Victimisation'. In Wortley R. and Townsley M. Environmental Criminology and Crime Analysis. $\left(2^{\text {nd }}\right.$ ed). London: Routledge.

Sidebottom, A. (2011) 'Repeat burglary victimization in Malawi and the influence of housing type and area-level influence' Security Journal, 2, 265-281.

Tilley N. (1999) After Kirkholt: Theory, Method and Results of Replication Evaluations. Crime Prevention Unit Paper \$7. London: Home Office.

Titus R.M. and Gover A.R. (2001) 'Personal Fraud: The Victims and the Scams'. In G.Farrell and K.Pease (eds) Repeat Victimisation: An Overview. Guilderland NY: Harrow and Heston

Trickett A., Osborn D., Seymour J. and Pease K, (1992)'What Is Different About High Crime Areas?' British Journal of Criminology 32, 81-89.

Tseloni A. and Pease K. (2003) 'Repeat Personal Victimisation: Boosts or Flags?' British Journal of Criminology, 43, 196-212.

Tseoni A. and Pease K. (2004) 'Repeat Personal Victimisation: Random Effects, Event Dependence and Unexplained Heterogeneity'. British Journal of Criminology, 44, 931-945.

Tseloni A., Wittebrood K., Farrell G. and Pease K. (2004) 'Cross-National Comparative Test of Routine Activities and Lifestyle Theories'. British Journal of Criminology, 44, 66-91.

Walby, S. and Myhill, A. (2001) 'New survey methodologies in re s e a rching violence against women', British Journal of Criminology, 41, 3, 502-522.

Walby S. and Allen J. (2004) 'Domestic violence, sexual assault and stalking: Findings from the British Crime Survey'. Home Office Research Study 276. London: Home Office.

Walby, S., Towers, J. and Francis, B. (2016) 'Is violent crime increasing or decreasing? A new methodology to measure repeat attacks making visible the significance of gender and domestic relations' British Journal of Criminology 56, 1203-1234.

Weisburd D. (2015) 'The law of crime concentration and the criminology of place'. Criminology 53,133-157 